\title{
A New Look at the Pathogenesis of the Meconium Aspiration Syndrome: A Role for Fetal Pancreatic Proteolytic Enzymes in Epithelial Cell Detachment
}

\author{
VADIM A. IVANOV, IRA H. GEWOLB, AND BRUCE D. UHAL \\ Departments of Pediatrics/Neonatology [V.A.I., I.H.G.] and Physiology [B.D.U.], Michigan State University, East Lansing, \\ Michigan 48823
}

\begin{abstract}
We hypothesized that fetal pancreatic digestive enzymes play a role in the lung damage after meconium aspiration. We studied the effect of meconium on the A549 alveolar epithelial cell line. The exposure of the cells to 0.5 to $5 \%$ meconium resulted in significant disruption of connections between A549 cells and caused dose-dependent cell detachment, without signs of cell death. A protease inhibitor cocktail prevented the A549 cell detachment induced by meconium. After the exposure to $2.5 \%$ meconium, a protective effect was quantified by measuring light absorbance by gentian violet stain of still attached cells. The protease inhibitor cocktail and chymostatin showed significant protective effects, increasing the number of attached cells by 135 and $123 \%$, respectively $(p<0.05)$. Other individual protease inhibitors tested in the detachment assay (AEBSF, leupeptin, E-64, aprotinin, benzamidine, phosphamidon, and aminohexanoic acid) did not offer statistically significant protection. These results afford a new perspective on the pathophysiology of meconium aspiration syndrome (MAS). We speculate that disruption of intercellular connections and cell detachment from the basement membrane are key events in the pathology associated with MAS. The observed protective effects of protease inhibitors suggest that they may be useful in the treatment and/or prophylaxis of MAS. (Pediatr Res 68: 221-224, 2010)
\end{abstract}

$\mathrm{M}$ econium aspiration syndrome (MAS) is a persistent problem in neonatal medicine. Despite a relatively low incidence, it is responsible for as many as 1000 deaths annually in the United States alone (1). Severely affected babies require highly skilled care and complicated technologies to survive. These skills and technologies are not widely available even in the developed world. The broad view on MAS pathophysiology, incidence, impact, prophylaxis, and treatment modalities is well described in the series of recent reviews (1-4).

Currently used MAS treatment measures are all supportive in nature and do not directly affect the injurious actions of meconium on the lung. Thus, there is still no effective and safe treatment or prophylactic measure for MAS once the meconium has passed below the vocal cords into the lungs.

Research on the mechanisms of MAS-induced injury remains focused on events after the initial injury. Moreover,

Received October 5, 2009; accepted May 20, 2010.

Correspondence: Vadim A. Ivanov, M.D., Section on Neonatal-Perinatal Medicine, Department of Pediatrics, The University of Oklahoma Health Sciences Center, 1200 North Everett Drive, ETNP 7504, Oklahoma City, OK 73190; e-mail: vadim2@earthlink.net

Presented at the 2008 Annual Meeting of the Pediatric Academic Societies in Honolulu, Hawaii. there is a paucity of ideas and research on how meconium actually damages lungs, apart from mechanical obstruction of the airways. Despite the fact that the pathogenicity of meconium is attributed to its chemical composition (which makes it thick, viscous, sticky, and in some way damaging to pulmonary tissues) and a wealth of studies on its particular constituents, there is little literature on attempts to use this knowledge to explain mechanisms of meconium effects on the tracheobronchial tree.

In a recent article, we hypothesized that fetal pancreatic enzymes that are present in meconium might play a direct role in the pathogenesis of MAS through digestion of pulmonary tissues (5). Although the presence of pancreatic proteolytic enzymes in human feces is a well-established fact (6), there is still no firm consensus regarding presence of the enzymes in the meconium. The majority of researchers report the presence of proteolytic enzymes in meconium in concentrations well above ones capable of protein digestion. For example, Mullinger and Palasi (7) found the average concentrations of trypsin and chymotrypsin in the first-day meconium to be 73 and $184 \mu \mathrm{g} / \mathrm{g}$, respectively. These numbers significantly exceed the final concentrations of 0.3 to $3 \mu \mathrm{g} / \mathrm{mL}$ and 1 to 25 $\mu \mathrm{g} / \mathrm{mL}$, respectively, used in laboratory conditions for protein hydrolysis with these enzymes (8). A few report the lack of particular enzymes in the first-day meconium. Good overviews of the data are presented in relatively old journal reviews $(9,10)$ and a recently published text $(11)$. The overall consensus is that meconium contains some proteolytic enzymes even at its first appearance. In real clinical situations, the presence or absence of particular enzymes are of little relevance. The final enzymatic activity of meconium would be determined by an interplay between pancreatic and brush border enzymes, bile, and electrolytes. Because of this, we found it reasonable to study the role of proteolytic enzymes in the pathology of MAS by attempting to inhibit the enzymes and evaluate if this inhibition could offer any protection in a MAS model.

Therefore, the aim of this study was to test the hypothesis that proteolytic enzymes play a role in the pathogenesis of MAS in an in vitro model of meconium-induced lung injury.

Abbreviations: MAS, meconium aspiration syndrome 


\section{METHODS}

In the first series of experiments, we evaluated the effect of meconium on pulmonary epithelial cells (A549 cell line) using direct phase-contrast microscopy. In this experiment, we discovered an effect that has not been noted previously-meconium caused massive cell detachment from the surface and from other cells (see Results section).

This novel effect was used to construct a new in vitro model of MAS. We then evaluated whether there is a grossly visible protective effect of protease inhibitors on meconium-mediated cell detachment.

Finally, we quantified the observed effects of epithelial cell injury by meconium and the protective effects of a variety of protease inhibitors using a modified quantitative cell detachment assay (12) for use in our in vitro model. In brief, A549 cells attached to a surface were exposed to meconium, and then, the detached and loosely attached cells were removed, followed by measurement of the number of remaining attached cells (see below).

Cell preparation. The human lung adenocarcinoma A549 cell line (American Type Culture Collection, Manassas, VA) was grown, maintained, and handled according to the supplier's manual in Ham's F12 medium (American Type Culture Collection), with $10 \%$ fetal bovine serum (FBS; GIBCO, Grand Island, $\mathrm{NY}$ ), to achieve $\sim 90 \%$ confluence at $37^{\circ} \mathrm{C}$ in $5 \% \mathrm{CO}_{2}$ (water-jacketed US autoflow automatic $\mathrm{CO}_{2}$ incubator; Nuaire, Plymouth, $\mathrm{MN}$ ); $\mathrm{CO}_{2}$ was supplied by Airgas Great Lakes (Independence, $\mathrm{OH}$ ). The cells were then dissociated with $0.5 \%$ trypsin, washed with serum-free Ham's F12 medium, redispersed in medium containing $10 \%$ FBS, and then plated in a 48 - or 96 -well plate $(\sim 50,000$ cells per well). By 18 to $24 \mathrm{~h}$, the seeded cells established a monolayer with $\sim 90 \%$ confluence at $37^{\circ} \mathrm{C}$ in $5 \% \mathrm{CO}_{2}$; they were then used in the experiments. Before the experiments, the cells attached to the wells were thoroughly washed $(\times 3)$ using serum-free Ham's F12 medium.

Meconium collection, storage, and preparation. First-pass meconium was collected from random anonymous healthy babies in the full-term nursery at Sparrow Hospital, Lansing, Michigan. The collection of the meconium was exempted from review by the institutional review board of the Sparrow Hospital, Lansing MI. The meconium was stored at $+4^{\circ} \mathrm{C}$ for no more than $24 \mathrm{~h}$ and then transported on ice to the laboratory. The meconium samples from seven babies were pooled, thoroughly mixed, divided into small aliquots, and kept at $-20^{\circ} \mathrm{C}$ until use. On the day of experiment, meconium was thawed at room temperature, diluted to $10 \%$ (wt/vol) with Ham's F12 medium, and dispersed by vigorous vortexing for $10 \mathrm{~min}$. The resultant suspension was centrifuged at $3000 \times \mathrm{g}$ for $20 \mathrm{~min}$ at $+4^{\circ} \mathrm{C}$. The supernatant was further filtered and sterilized using a $22-\mu \mathrm{m}$ filter and then used in the experiments.

Initial test of meconium effect on the A549 cells. The cells were exposed to meconium diluted in serum-free Ham's F12 medium to final concentrations of 0.5 to $5 \%$. After $18 \mathrm{~h}$, the effects were observed using a direct phasecontrast microscope. Control cells were incubated in serum-free Ham's F12 medium. The viability of meconium-exposed cells was evaluated with propidium iodide (positive in dead cells) and acridine orange (positive in live cells) staining.

In the second series of experiments, the A549 cells were exposed in the same manner to Ham's F12 medium (control), 5\% meconium alone, and a proprietary protease inhibitor cocktail (Complete Mini, EDTA-free; Roche, Nutley, NJ) diluted according to the manufacturer's recommendations, alone or with meconium.

For quantification purposes, the cells were exposed in the same way to meconium dilutions between 0.5 and $5 \%$ and to $5 \%$ meconium with concurrently added protease inhibitor cocktail; controls were incubated with F12 medium alone or with addition of the protease inhibitor cocktail. After $18 \mathrm{~h}$ incubation, the cells were photographed with a digital camera, and the surface covered by the cells was measured using digital image manipulation software (Photoshop 6.0).

Detachment assay. We used a slightly modified detachment assay previously described by Marrion and Riley (12). Cells were prepared as described above. Immediately after washing with Ham's F12 medium, the cells were exposed to $2.5 \%$ meconium with or without protease inhibitors (Protease Inhibitor Panel; Sigma Chemical, Co., St. Louis, MO) for $18 \mathrm{~h}$ at $37^{\circ} \mathrm{C}$ in $5 \%$ $\mathrm{CO}_{2}$. The list of the protease inhibitors and the final concentrations used are shown in the Table 1. Control wells (no meconium) in Ham's F-12 medium were incubated with or without the inhibitors. After incubation, the medium was gently aspirated, and detached and loosely attached cells were removed by gentle standardized washing with phosphate buffer solution using a multichannel pipette. The remaining cells were fixed with $70 \%$ ethanol (AAPER Alcohol and Chemical Co., Shelbyville, KY) at $-20^{\circ} \mathrm{C}$ for $20 \mathrm{~min}$. After the removal of the ethanol, the cells were stained with gentian violet (Sigma Chemical Co., St. Louis, MO) for another $15 \mathrm{~min}$ at room temperature. The excess dye was removed by washing $(\times 6)$ with distilled water.
Table 1. List of protease inhibitors tested for in the detachment study for protective effect against meconium exposure

\begin{tabular}{lc}
\hline \multicolumn{1}{c}{ Protease inhibitor } & Final concentration \\
\hline Chymostatin & $10 \mathrm{mg} / \mathrm{mL}$ \\
AEBSF [4(2-aminoethyl) benzenesulfonyl & $1 \mathrm{mM}$ \\
$\quad$ fluoride hydrochloride] & $100 \mathrm{mM}$ \\
Leupeptin & $10 \mathrm{mM}$ \\
E 64 [trans-epoxysuccinyl-L -leucylamido & \\
$\quad$ (4-guanidino) butane] & $100 \mathrm{nM}$ \\
Aprotinin & $1 \mathrm{mM}$ \\
Benzamidine & $10 \mathrm{mM}$ \\
Phosphamidon & $5 \mathrm{mg} / \mathrm{mL}$ \\
Aminohexanoic acid & As per manufacturer \\
Protease inhibitor cocktail & \\
$\quad$ (Complete & \\
by Roche) & \\
\hline
\end{tabular}

The concentrations of the inhibitors were used as suggested for use in cell culture by the manufactures.

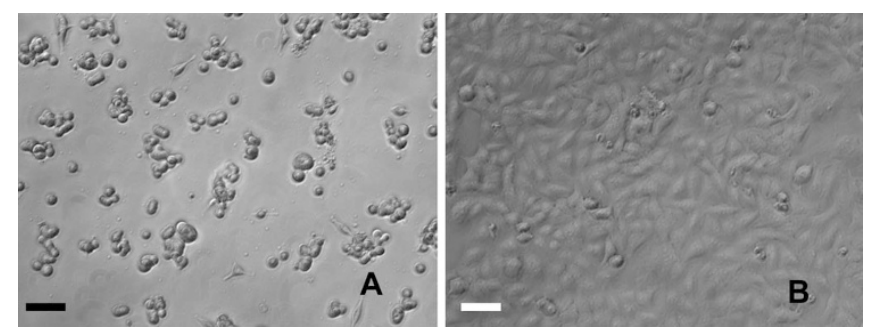

Figure 1. The effect of meconium on A549 epithelial cells. The A549 cells exposed to $5 \%$ meconium became round and detached off the surface and from each other $(A)$, compared with the control cells, which stayed well attached and spread over the bottom of the culture well $(B)$. Magnification $200 \times$. The scale bar is $100 \mu \mathrm{m}$.

Gentian violet incorporated in the attached cells was eluted by $33 \%$ acetic acid (Sigma Chemical Co.) and its concentration was measured with a plate reader (BioRad, Carlstad, CA) at a wavelength of $540 \mathrm{~nm}$. The average absorbance of the blank wells was subtracted from the absorbance of each test or control well.

Statistical analysis. The initial experiments were performed once in three wells. Each experiment of cell detachment was performed in three wells and was repeated three times. All results were compared using ANOVA with the Holm-Sidak post hoc test.

\section{RESULTS}

The effect of meconium on A549 cells is shown in Figure 1. As can be seen, the cells exposed to $5 \%$ meconium became round and detached from the surface and from each other (Fig. $1 A)$, compared with the control wells, where cells stayed well attached and spread over the bottom of the culture well (Fig. $1 B)$. If the culture vial containing meconium-exposed cells was shaken, the cells were noted to be floating, unlike the control cells, in a manner similar to cells after exposure to trypsin. Quantitatively, the surface covered by the cells is shown in Figure 2. In the detachment assay, 50\% detachment was achieved with a $2.5 \%$ final meconium concentration, whereas lower concentrations had lower detachment rates. The effect of the lowest concentration ( $0.1 \%$ meconium) was indistinguishable from control values in the detachment assay. Approximately, 0.1 to $0.5 \%$ of meconium caused less ( $\sim 30$ to $40 \%$ ) detachment than $2.5 \%$ meconium, even though meconium in final concentrations as low as $0.5 \%$ was capable of causing obvious morphologic changes in the cell monolayer, 


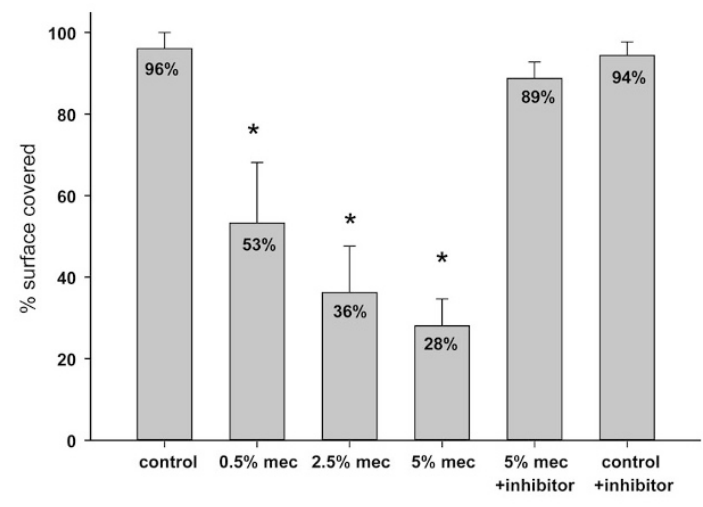

Figure 2. Percentage of surface covered by A549 cells exposed to different concentrations of meconium and effect of the protease inhibitor cocktail (Complete Mini by Roche). There was a significant reduction of the surface covered by the cells after the exposure to meconium and nearly complete prevention of the effect by addition of the protease inhibitor. *Significant difference $(p<0.01)$ vs controls, controls + inhibitor cocktail, and cells concurrently exposed to $5 \%$ meconium and the protease inhibitor cocktail.

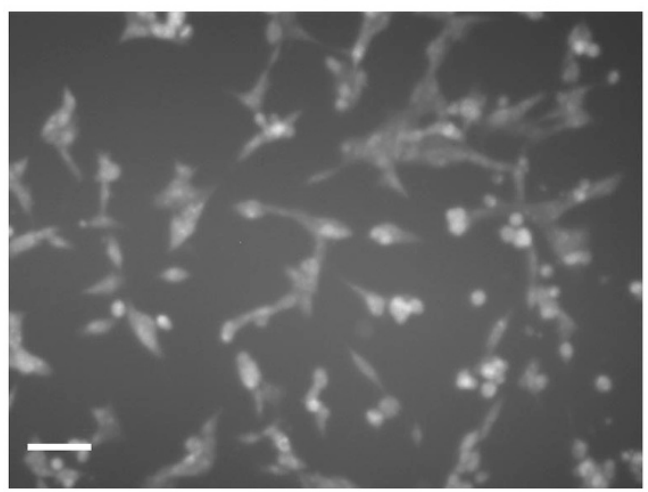

Figure 3. Acridine orange staining of detached cells (after treatment with $2.5 \%$ meconium) indicates cell viability through the ability to take up the dye and inability to take up propidium iodide (not shown). Magnification $200 \times$. The scale bar is $100 \mu \mathrm{m}$.

which was reflected by smaller surface covered by the cells. The detached cells from the $2.5 \%$ meconium solution were alive, as evidenced by positive staining with acridine orange (Fig. 3) and negative staining with propidium iodide (not shown). Addition of the proteolytic enzyme inhibitor cocktail (Complete Mini by Roche) to the wells completely protected the cells from the noxious effect of meconium (Fig. 4A). The cells stayed well attached to the surface and to each other (Fig. $4 B)$. The protease inhibitor alone had no detrimental effect (Fig. 4C). Control cells are shown in Figure 4D. The surfaces covered by the cells exposed to meconium alone and concurrently with protease inhibitor cocktail are shown in Figure 2.

Results of the quantitative detachment assay, expressed as OD, using a variety of protease inhibitors are given in Figure 5. As can be seen, statistical significance was achieved with Complete Mini and with chymostatin, which increased the number of attached cells by 135 and $123 \%$, respectively, when compared with cells exposed to meconium but no protease inhibitor. Other inhibitors approached but did not achieve statistical significance, possibly because of the low number of experimental assays.

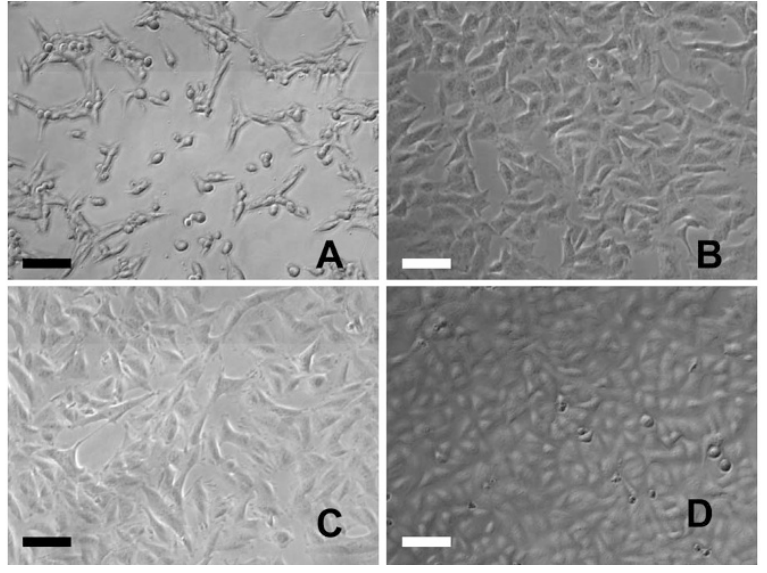

Figure 4. $A$, The effect of $2.5 \%$ meconium on the cells: the cells are rounded after the detachment from the well surface. $B$, Complete inhibition of the meconium-induced detachment by the protease inhibitor cocktail. $C$, Cells exposed to the protease inhibitor cocktail alone; no detrimental effect of the protease inhibitor is noted. $D$, Control cells (no meconium or protease inhibitor added). The cells are spread over the well surface and are well attached. Magnification $200 \times$. The scale bar is $100 \mu \mathrm{m}$.

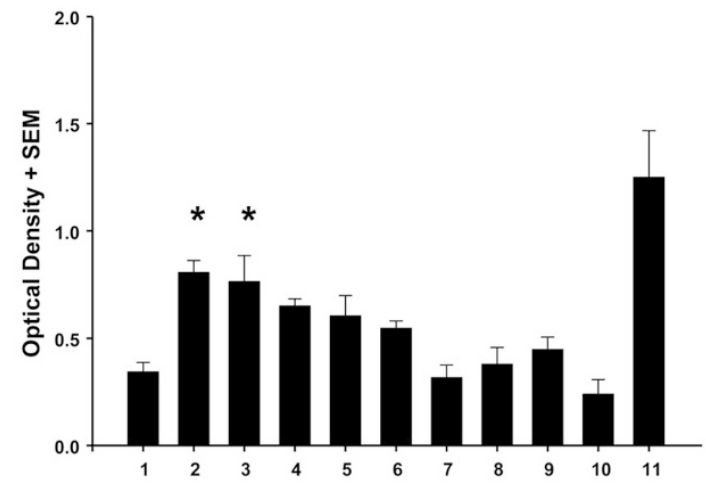

Figure 5. Quantified protective effects offered by protease inhibitors to A549 cells exposed to meconium in the cell detachment assay. The number of cells remaining attached is expressed in OD units. These results show a significant protective effect of the Roche protease cocktail (Complete Mini) and of chymostatin. The numbers below the bars represent the following composition of the reaction mixture: 1 , control: meconium, no inhibitor; 2 , meconium plus Complete by Roche; 3 , meconium plus chymostatin; 4 , meconium plus AEBSF; 5, meconium plus leupeptin; 6, meconium plus E 64; 7, meconium plus aprotinin; 8 , meconium plus benzamidine; 9 , meconium plus phosphamidon; 10, meconium plus aminohexanoic acid; 11, control: no meconium, no inhibitor. *Significant difference $(p<0.05)$ vs control (meconium but no inhibitor added, bar 1).

\section{DISCUSSION}

In this report, we describe a newly observed effect that might change our understanding of the sequence of events and pathophysiology of processes after meconium aspiration in newborns. The results of this in vitro study show that meconium is capable of detaching pulmonary epithelial cells from their base and from each other in vitro. Possible substances responsible for this injury are pancreatic digestive proteolytic enzymes present in the meconium. We also showed that proteolytic enzyme inhibitors could ameliorate this noxious effect of meconium. This serves as a first line of evidence supporting our initial hypothesis that fetal pancreatic proteolytic enzymes play a role in pulmonary tissue injury in patients 
with MAS. Interesting enough, meconium in relatively low concentration was capable of detaching the cells but did not cause cellular death, at least, not as detectable by the acridine orange and propidium iodide assays used here.

We speculate that besides pure mechanical obstruction, the very first phase in the pathogenesis of MAS is disruption of connections between bronchoalveolar epithelial cells and the basement membrane and other cell-cell connections. This may be a key event leading to the pathology seen in MAS.

Our study represents a first step into exploration of a possible role of pancreatic proteolytic enzymes in MAS and the peculiar mechanism of destructive action of these enzymes. The importance of the observed effects and relevance of them to the mechanisms of human disease obviously require confirmation with further research, including animal model and clinical studies. However, it is worth noting that this effect of respiratory tract epithelial cell detachment after the exposure to meconium had been previously observed in vitro $(13)$ and in an animal model $(13,14)$ but was thought to be an event secondary to cell death. In our experiments, we showed that cells exposed to meconium in concentrations less than was used by previous investigators $(13,14)$ did indeed detach cells from the surface but that the cells remained viable.

Zagariya et al. (15) demonstrated a protective effect of the protease inhibitor ZVAD-fmk in MAS by showing that this pan-caspase inhibitor prevented meconium-induced apoptosis. In view of our data, the protective effect of ZVAD-fmk might also include potentially nonspecific effects of the caspase inhibitor on fetal proteolytic enzymes in meconium, but further research will be required to address this possibility.

Disruption of cell attachment may not allow the cells to perform many of their functions, such as provision of a physical barrier. Synchronization of the ciliary apparatus requires good cell-to-cell connection and communication. The disruption of connections between cells and their base observed in this study on nonciliated model cells might be extrapolated to ciliated epithelium. We speculate that meconium is capable of disorganizing the evacuation activity of the ciliary apparatus. The destruction of intercellular connections may be another possible mechanism explaining the high frequency of pneumothoraces in MAS.

As a next step in the investigation of the role of proteolytic enzymes in MAS, the development of a suitable animal model is needed. The discovery of protease inhibitor protective effects in appropriate models of MAS might be explored further for development of new treatments and/or prophylactic modalities in MAS.

Acknowledgments. We thank Dr. Amal T. Abdul-Hafez and Dr. Leonid Volkov for help in the designing and executing the experiments. We also thank the nursing staff in the Newborn Nursery of Sparrow Hospital (Lansing, MI) for help in collecting the material for the study.

\section{REFERENCES}

1. Gelfand SL, Fanaroff JM, Walsh MC 2004 Controversies in the treatment of meconium aspiration syndrome. Clin Perinatol 31:445-452

2. Hofmeyr GJ 2009 What (not) to do before delivery? Prevention of fetal meconium release and its consequences. Early Hum Dev 85:611-615

3. de Beaufort AJ 2009 Early human development at the perinatal interface: meconium stained amniotic fluid (MSAF) and meconium aspiration syndrome (MAS). Early Hum Dev 85:605

4. Kääpä PO 2009 Meconium aspiration syndrome (MAS) — where do we go? Research perspectives. Early Hum Dev 85:627-629

5. Ivanov VA 2006 Meconium aspiration syndrome treatment-new approaches using old drugs. Med Hypotheses 66:808-810

6. Lankisch PG 1982 Exocrine pancreatic function tests. Gut 23:777-798

7. Mullinger M, Palasi M 1966 Tryptic and chymotryptic activity of stools of newborn infants. Pediatrics 38:657-659

8. Bergmeyer HU, Gawehn K 1974 Methods of Enzymatic Analysis. Academic Press, New York, NY, pp 1008, 1019

9. Antonowicz I, Shwachman H 1979 Meconium in health and in disease. Adv Pediatr 26:275-310

10. Harries JT 1978 Meconium in health and disease. Br Med Bull 34:75-78

11. Walker WA, Durie P, Hamilton JR, Walker-Smith JA, Watkins JB 1991 Pediatric Gastrointestinal Disease: Pathophysiology, Diagnosis, Management. B.C. Decker, Philadelphia, PA, pp 274

12. Marrion RM, Riley L 2000 Detection of cell detachment activity induced by Moraxella bovis. Am J Vet Res 61:1145-1149

13. Zagariya A, Bhat R, Uhal B, Navale S, Freidine M, Vidyasagar D 2000 Cell death and lung cell histology in meconium aspirated newborn rabbit lung. Eur J Pediatr 159:819-826

14. Mokra D, Tonhajzerova I, Mokry J, Drgova A, Petraskova M, Calkovska A, Javorka K 2008 Rapid cardiovascular effects of dexamethasone in rabbits with meconiuminduced acute lung injury. Can J Physiol Pharmacol 86:804-814

15. Zagariya A, Bhat R, Chari G, Uhal B, Navale S, Vidyasagar D 2005 Apoptosis of airway epithelial cells in response to meconium. Life Sci 76:1849-1858 